\title{
Pathological findings associated with stillborn babies
}

\author{
Sofiya.C ${ }^{1}$, B. Pushpa ${ }^{2}$, S. Selvi ${ }^{3}$, Hemavathi ${ }^{4}$ \\ ${ }^{1}$ Dr. Sofiya.C, Assistant Professor, ${ }^{2}$ Prof. Dr. B. Pushpa, Professor, ${ }^{3}$ Dr. S. Selvi, Assistant Professor, ${ }^{4}$ Dr. Hemavathi, \\ Assistant Professor, all authors are affiliated with department of Pathology, Govt. Kilpauk Medical College, Chennai, \\ Tamilnau, India
}

Address for correspondence: Dr. Sofiya. C, Email: csofiyac@gmail.com

\begin{abstract}
Introduction: Fetal death rate and Perinatal Mortality rate are important indicators of a country's Health care system. Stillbirth forms a prime contributing factor in deciding these rates. But the causes of Stillbirth and autopsy findings associated with Stillbirth remains a gray zone. The aim of this study is to analyse the pathological autopsy findings associated with spontaneously expelled stillbirth babies and placenta. Materials and Methods: This is a retrospective study conducted in Department of Pathology, Govt. Kilpauk Medical College, Chennai for a period of 1 and half years. 29 Stillborn cases were received in our department during this period. Fetal autopsy was done in these cases by using a standard protocol. The external, internal examination findings and histopathological findings of both fetus and Placenta were analysed and compared with the Antenatal clinical findings. Results: Stillbirth is more common in the third trimester constituting $72.4 \%$ cases and peaks at $27-30$ weeks of gestation. Placental pathology is more frequently associated with stillbirth with $44.8 \%$ followed by Fetal causes with $34.5 \%$ and maternal causes identified in $6.9 \%$ cases. In the second trimester stillbirths fetal causes are common and in third trimester placental pathologies were common. Among the fetal causes, congenital anamolies are seen in all cases with CNS and Kidney anamolies being the commonest. Among the Placental causes, placental infarct is seen in most of the cases. In $13.8 \%$ cases, no pathology identified even after complete autopsy. Conclusion: A Complete schematic autopsy of fetus and placenta along with a good knowledge and correlation of pathological and clinical findings help in arriving at a diagnosis of cause of fetal demise. A correct diagnosis of the cause of stillbirth can alleviate parents worries and helps the clinician in deciding the counselling, care and management of future pregnancies.
\end{abstract}

Keywords: Stillbirth, Autopsy, Congenital anamolies, Placental pathology

\section{Introduction}

A healthy live born baby without complication is the main goal of pregnancy care. Delivering a dead fetus is an unexpectable shock to the Parents and clinicians that causes major physical, economical and psychological insult. Fetal demise can occur at any period of pregnancy. Stillbirth is the commonly used term for fetal demise. WHO defines stillbirth as death of fetus after 20 weeks of gestation or delivery of a baby without signs of life [1]. Death of fetus during 20-27 weeks of gestation is called early fetal death and death of fetus after 28 weeks is called late fetal death [2]. The measure of stillbirth acts as an important indicator of the efficacy of a nation's health care system. About 4

Manuscript received $04^{\text {th }}$ December 2016

Reviewed: $12^{\text {th }}$ December 2016

Author Corrected: 20 ${ }^{\text {th }}$ December 2016

Accepted for Publication: $27^{\text {th }}$ December 2016 million cases of stillbirth are reported worldwide each year and in Developing countries there is a stillbirth reported for every 200 pregnancies [3]. India is one of the countries with high stillbirth rate and it ranges from 20-66/1000birth in different states and two third of these cases were from rural areas [4]. A variety of causes and contributing factors have been explained for stillbirth and many strategies were made to reduce stillbirth rate. Still for many cases the cause is unexplained. There is no well defined International classification system for the cause of stillbirth and hence the datas on pathological findings associated with stillbirth are limited [5]. This study was conducted to find the autopsy and histopathological findings associated with stillborn fetus. 


\section{Materials and Methods}

This study was conducted in Department of Pathology, Government Kilpauk Medical College, Chennai for a period of one and half years from January 2015 to June 2016. All spontaneously expelled dead fetuses received along with placenta in our department which crossed 20 weeks of gestation were taken for the study. A total of 29 stillborn babies were received during this period. First trimester abortions, molar pregnancies and ectopic pregnancies were excluded from the study. Antenatal history and clinical findings were obtained. Fetal autopsy was done according to the guidelines by Royal college of Pathologists [6]. This include complete external and internal examination of Fetus and placenta followed by histopathological examination. The external examination of fetus include weight, head circumference, crown heel and crown rump lengths, foot length, Maceration changes, any congenital malformation or deformities and meconium staining. The internal examination of fetus includes complete examination of cranial, thoracic and abdominal cavities, subcutaneous fat thickness and description of major organs incuding weight. The placental examination include Size, weight, intactness of membrane, fetal, maternal and cut surfaces followed by umbilical cord length and vessels. For histopathological examination blocks were taken from lungs, liver, kidney, adrenals, brain and pancreas-one block from each. Blocks were also taken from cord, membranes, normal parenchyma and any other grossly visible lesions from Placenta. Autopsy findings, histopathological findings and clinical details like maternal conditions were analysed. These cases were catagorised based on the cause like Maternal, Fetal and Placental causes according to the classification system proposed by Cunningham and Hollier [7]. Chromosomal anomalies, Nonchromosomal birth defects, Non-immune hydrops, Infections-viruses/bacteria/protozoa were included under Fetal causes. Abruption, Fetal-maternal hemorrhage, Cord accident, Placental insufficiency, Intrapartum asphyxia, Placenta Previa, Twin to twin transfusion, Chorioamnionitis were included under Placental causes. Diabetes, Hypertensive disorders, Trauma, Abnormal labour, Sepsis, Acidosis, Hypoxia, Uterine rupture, Post-term pregnancy, Drugs, Antiphospholipid antibodies were included under Maternal causes.

\section{Results}

Totally 29 spontaneously expelled dead fetus were received during this period. 18 cases were male babies and 11 cases were female babies. In our study, late fetal death $(\geq 28$ weeks) is more common with 21 cases $(72.4 \%)$ than early fetal death (20-27 weeks) which constitute 8 cases(27.6\%). The maternal age in this study ranges from 19 years to 35 years and stillborn peaks at 22 years of maternal age. As per the Cunningham and Hollier classification system, the causes were catagorised. Of the 29 cases, 10 cases $(34.5 \%)$ have fetal causes, 13 cases $(44.8 \%)$ have Placental causes and 2 cases $(6.9 \%)$ have maternal causes and the cause could not be explained in 4 cases $(13.8 \%)$ even after complete autopsy and histopathological examination. Placental causes are slightly predominant in the older age group compered with fetal causes which is common in younger age group. In the second trimester, fetal causes are common and in third trimester placental causes are common. The 2 maternal causes were seen in third trimester. All the fetal causes have fetal congenital anamolies with neural tube defect, heart defect and cystic kidneys predominant followed by Musculoskeletal defects, abdominal wall defects and facial dysmorphism. Of the 13 cases having Placental pathologies, 4 cases have extensive placental infarction, 3 cases have placental insufficiency changes, 2 cases have chorioamnionitis and 4 cases have other pathologies like placental cyst, abruption, extensive perivillous fibrin deposition and hypoplastic placenta. By classifying according to Tulip classification, Placenta bed pathologies constitute predominant with $38.5 \%$ cases followed by Placental parenchymal pathologies with $30.7 \%$ cases. 4 cases have no placental and fetal pathologies identified in the fetus and placenta and histopathological examination. The maternal causes have history of Preeclampsia.

\section{Table 1: Causes of Stillbirth}

\begin{tabular}{|l|l|l|l|}
\hline \multirow{2}{*}{ Cause } & No. of cases & \multirow{2}{*}{ Total } \\
\cline { 2 - 4 } & Early fetal death (13 cases) & Late fetal death (16 cases) & \\
\hline Placental causes & 3 & 10 & $13(44.8 \%)$ \\
\hline Fetal causes & 8 & 2 & $10(34.5 \%)$ \\
\hline Maternal causes & - & 2 & $2(6.9 \%)$ \\
\hline Unexplained & 2 & 2 & $4(13.8 \%)$ \\
\hline
\end{tabular}


Table 2: Placental pathology based on Tulip classification

\begin{tabular}{|l|l|l|}
\hline TULIP classification & Pathological finding & No of cases \\
\hline Placental bed pathology & Infarction, Abruption & $5(38.5 \%)$ \\
\hline Placental developmental pathology & Hypoplastic placenta & $1(7.7 \%)$ \\
\hline Placental parenchymal pathology & Extensive perivillous fibrin, Syncitial knots & $4(30.7 \%)$ \\
\hline Cord abnormalities & - & Nil \\
\hline Others & Placental cyst & $1(7.7 \%)$ \\
\hline Chorioamnionitis & Inlammatory infiltrate of membrane & $2(15.4 \%)$ \\
\hline
\end{tabular}

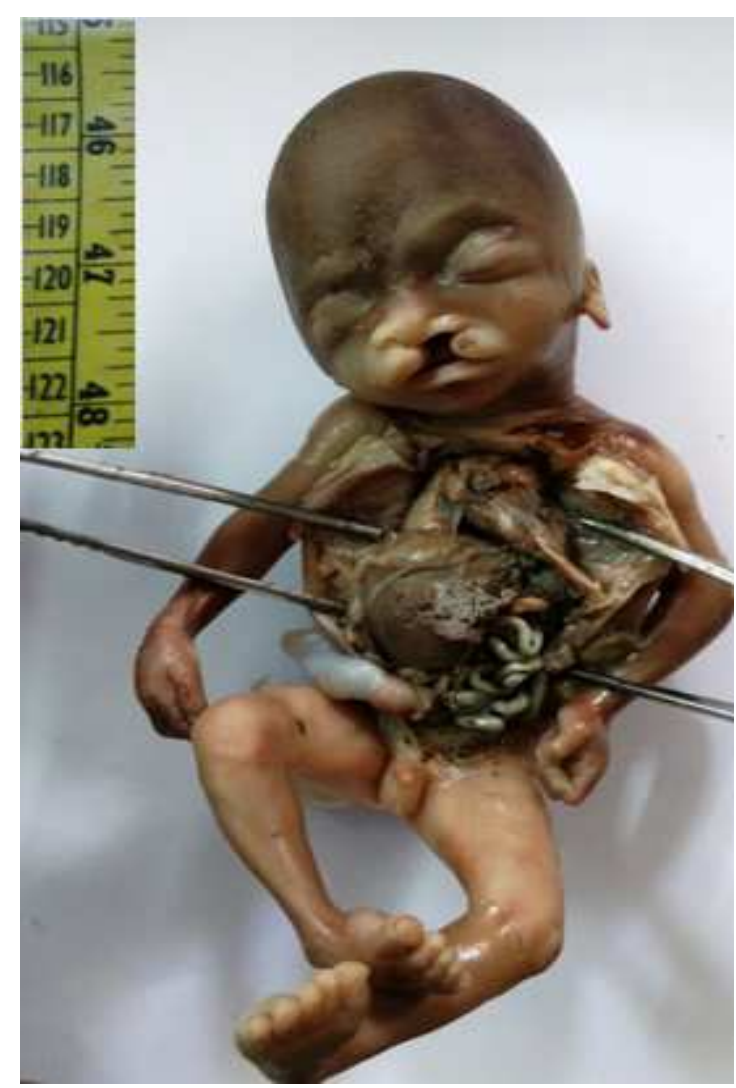

Fig-1: Stillborn baby showing cleft lip and cleft palate
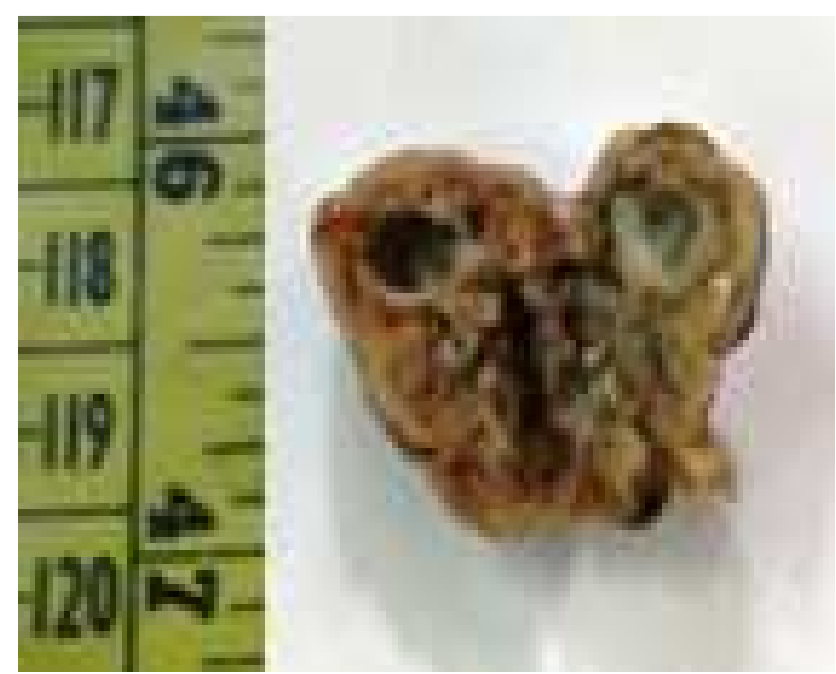

Fig-2: Stillborn baby kidney showing Multiple cysts

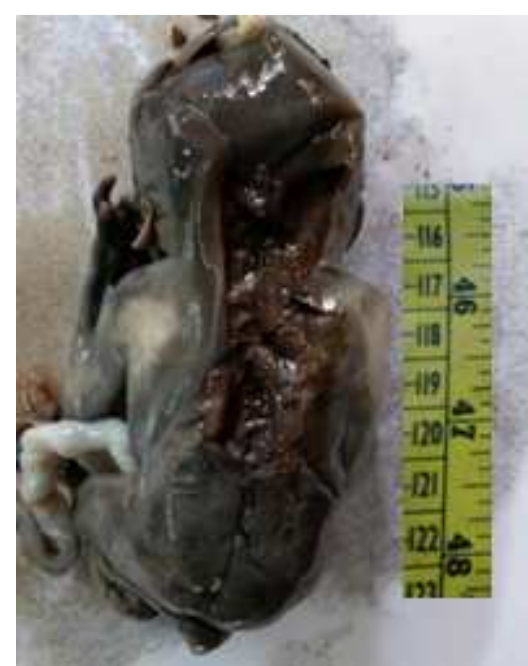

Fig 3: Stillborn baby showing neural tube defect 


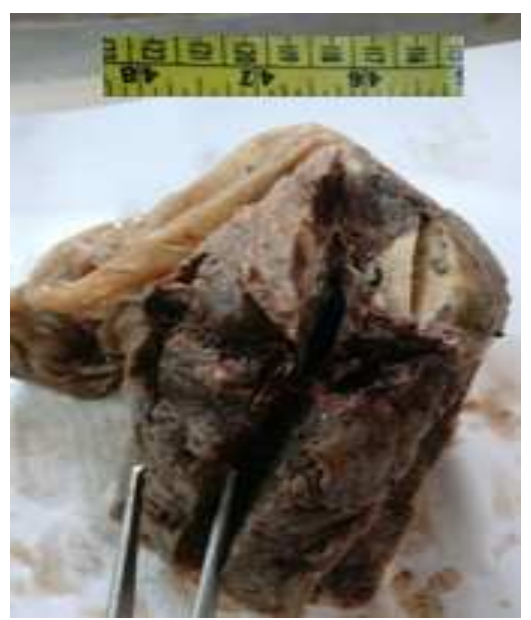

Fig 4: Gross picture of placenta showing Infarction

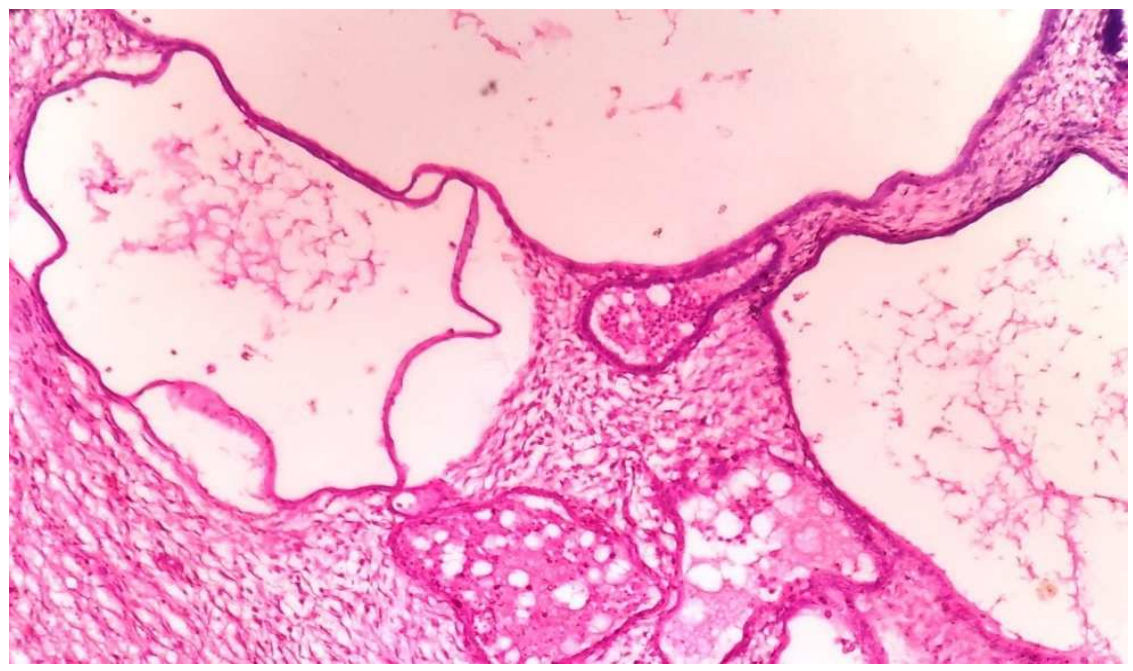

Fig 5: Microscopic picture of cystic kidney showing multiple cysts lined by flattened to cuboidal epithelium (100x)

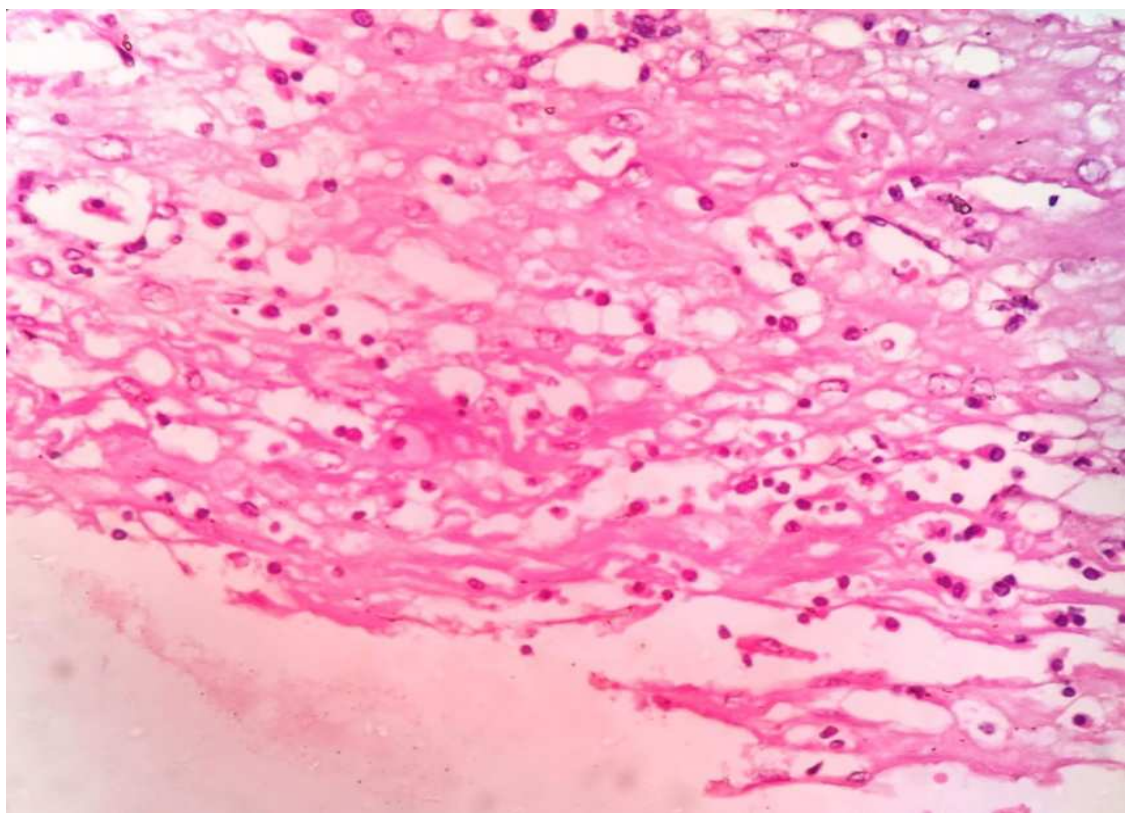

Fig 6: Structure of Placental membranes infiltrated by inflammatory cells- Chorioamnionitis (400x) 


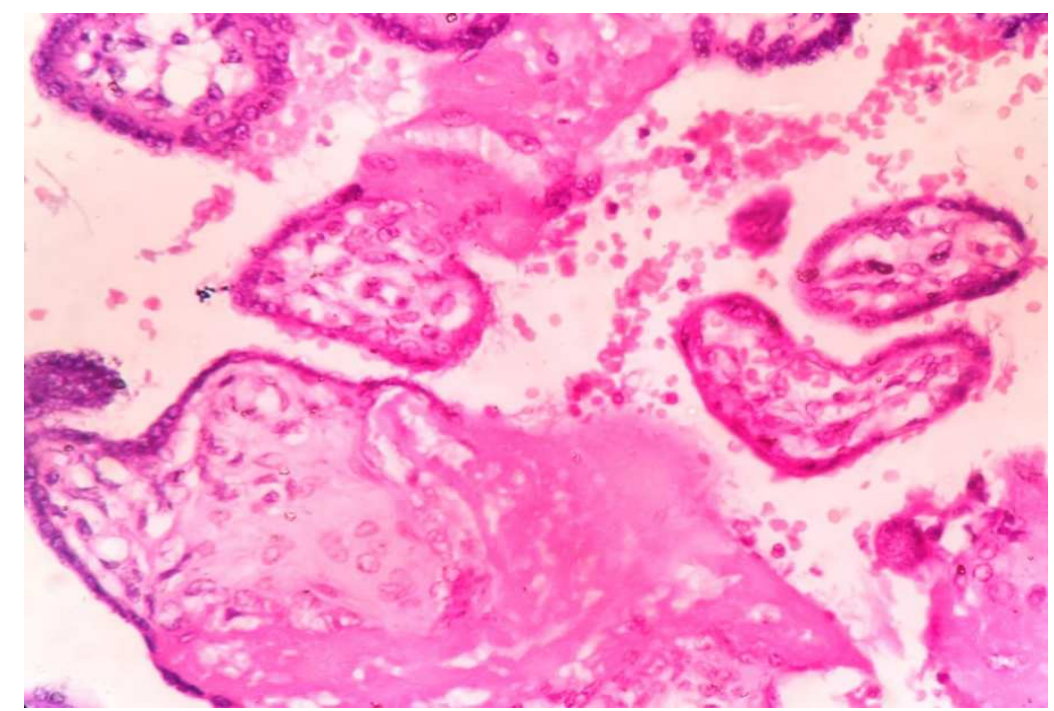

Fig 7: Picture showing perivillous fibrin deposition (400x)

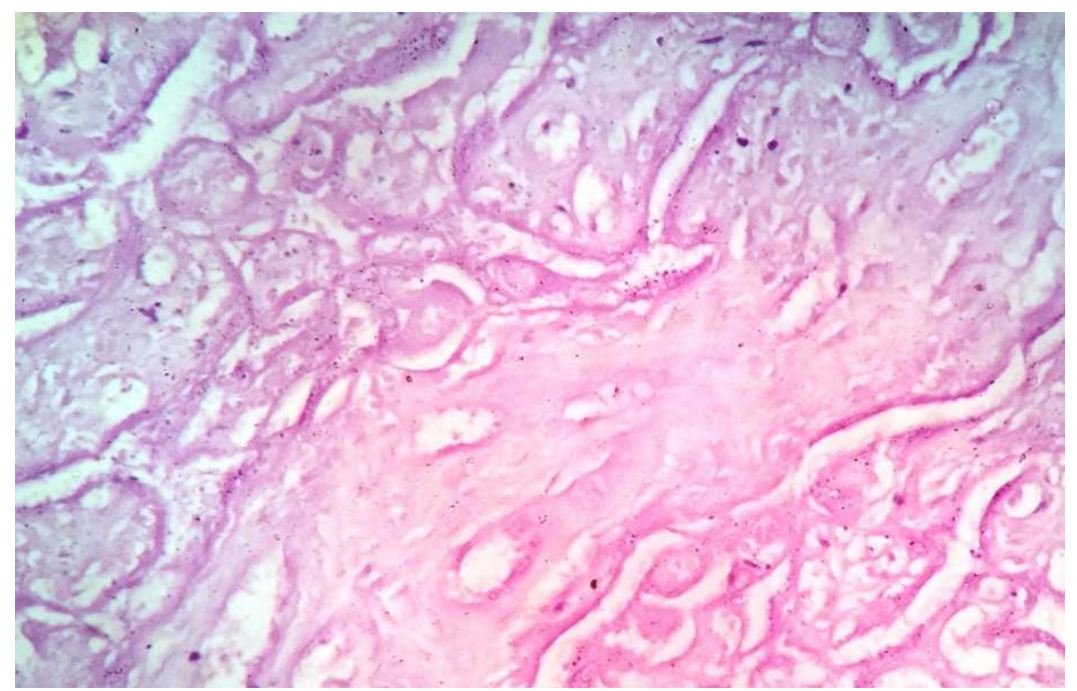

Fig 8 : Placental infarction $(400 x)$

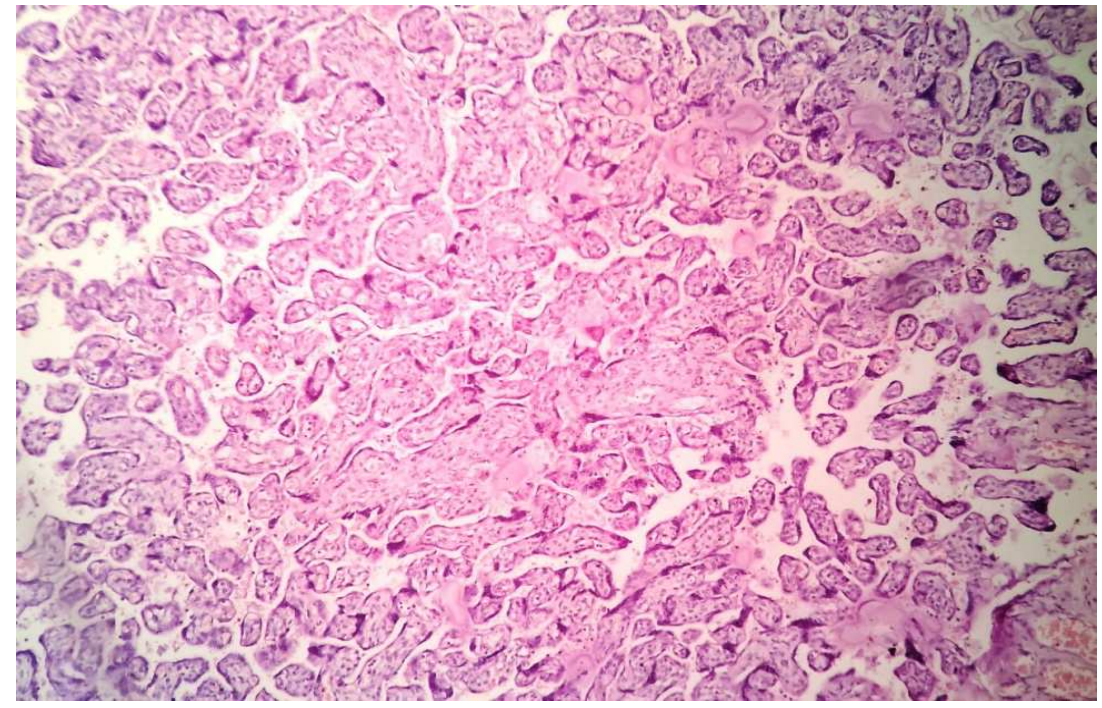

Fig 9: Placenta with syncitial knots (100) 


\section{Discussion}

Fetal autopsy including complete gross and histopathological examination of placenta is very important to identify the cause of stillbirth. Identifying the cause and classifying them remains a gray zone in Pathology as there is a lack or only limited training for the pathologist in Perinatal pathology. There are more than 20 classification systems based on perinatal pathologies [8]. But there is no single standardized classification system available for the causes of stillbirth. Korteweg et al proposed a classification system called Tulip classification system in 2006 and found out a good inter-rater agreement with low percentage of unknown causes [9]. Fleurisca et al studied 750 cases of fetal death and catagorised according to Tulip classification system which include Placental bed pathologies, placental developmental pathologies, placenta parenchymal pathologies, Umbilical cord pathologies and others [10]. They found out Placental bed pathologies are predominant with $33.6 \%$ of cases. Our study also shows similar results with $38.5 \%$ cases having placental bed pathologies. Uroos Fatima et al studied 14 fetal autopsies and found out that placental causes predominate with $43.6 \%$ cases followed by fetal causes with $35.7 \%$. [11]. our study also shows similar results with predominant placental pathologies followed by fetal pathology. Study by Faye Peterson et al found out that among the fetal causes, congenital anamolies forms the highest percentage and include neural tube defects and congenital heart disease. Our study also shows similar results with neural tube defects, heart defects and renal anamolies being the predominant [12]. Some studies have also shown that congenital anamolies are common in the low birth weight babies [13]. Ptacek et al did a systemic review of placental pathologies associated with stillbirth. They analysed 41 studies and found that pathological studies on stillbirth are limited in low and middle income countries like India and the Clinical utility of the pathological findings associated with stillborn babies remains as a question mark as different pathologist uses a different classification system and different terminology [14], [15]. Hence a standardized methodological approach and terminology should be developed and followed universally.

\section{Conclusion}

Fetal autopsy and Placental examination including histopathological examination should be done all cases of fetal death. By following a standard classification system one can diagnose the cause of unexplained fetal death. Identifying the cause of fetal death is very important as it helps the clinicians to counsel the parent regarding the cause, future pregnancy care and management. Since Placental pathologies are predominant, pregnancy care and future studies should be focussed on clinical conditions associated with placental pathologies.

Funding: Nil, Conflict of interest: None initiated, Permission from IRB: Yes

\section{References}

1. International Statistical Classification of Disease and related Health problems. WHO.2006.Tenth revision (ICD-10);2, Geneva, Switzerland:

2. Wanda Denise Barfield. Standard terminology for fetal, Infant and Perinatal deaths, American Acadamy of

Pediatrics. 2011 July;128(1):177-181. DOI : 10.1542/peds;2011-1037.

3. Silver RM. Fetal death. Obstet Gynecol. 2007 Jan;109(1):153-67. doi:10.1097/01.AOG.0000248537.89739.96

4. Stillbirths. Maternal, newborn, child and adolescent health. World Health Organization.2016-09-29.

5. Leisher, Susannah Hopkins. Classification system for causes of Stillbirth and neonatal death. 2009-2014: an assessment of alignment with characteristics of an effective global system. BMC pregnancy and childbirth. 2016;Sep 16;269. DOI: 10.1186/s12884-016-1040-7.

6. Royal College of Obstetricians and Gynecologists. Joint working party report on Fetal and perinatal pathology. London (UK): RCOG; 2001; June.

7. Pauli RM, Reiser CA. Wisconsin Stillbirth Service Program: II. Analysis of diagnoses and diagnostic categories in the first 1,000 referrals. Am J Med Genet. 1994 Apr 1;50(2):135-53.

8. F. J. Korteweg, S. J. Gordijn et al. A Placental Cause of Intra-uterine Fetal Death Depends on the Perinata Mortality Classification system used. Placenta. 2008;July; $29 . \quad 71-80 . \quad$ DOI: 10.1016/j.placenta.2007.07.003 
9. FJ Korteweg, SJ Gordijn et al, The Tulip Classification of Perinatal Mortality: introduction and multidisciplinary inter-rater agreement. BJOG- 2006; April :113(4), 393-401. DOI : 10.1111/j.14710528.2006.00881.

10. Korteweg FJ, Erwich JJ, Holm JP, Ravisé JM, van der Meer J, Veeger NJ, Timmer A. Diverse placental pathologies as the main causes of fetal death. Obstet Gynecol. 2009 Oct;114(4):809-17. doi: 10.1097/AOG.0b013e3181b72ebe.

11. Fatima U, Sherwani R, Khan T, Zaheer S. Foetal autopsy-categories and causes of death. J Clin Diagn Res. $2014 \quad$ Oct;8(10):FC05-8. doi: 10.7860/JCDR/2014/9226.4920. Epub 2014 Oct 20.
12. Faye-Petersen OM, Guinn DA, Wenstrom KD. Value of perinatal autopsy. Obstet Gynecol. 1999 Dec;94(6):915-20.

13. Pushpa B, Subitha S, Lokesh Kumar V. Study on various congenital anamolies in fetal autopsy. Int J Med Res Rev 2016;4(9);16671674.DOI:10.17511/ijmrr.2016.i09.26.

14. Ptacek I, Sebire NJ, Man JA, Brownbill P, Heazell AE. Systematic review of placental pathology reported in association with stillbirth. Placenta. 2014 Aug;35(8):552-62. doi: 10.1016/j.placenta.2014.05.011. Epub 2014 Jun 6.

15. Sankar VH, Phadke SR. Sankar VH, Phadke SR. Clinical utility of fetal autopsy and comparison with prenatal ultrasound findings. J Perinatol. 2006 Apr;26(4):224-9.

\section{How to cite this article?}

Sofiya.C, B. Pushpa, S. Selv, Hemavathi. Pathological findings associated with stillborn babies. Int J Med Res Rev 2016;4(12):2135-2141.doi:10.17511 /ijmrr. 2016.i12.10. 